\title{
EL MODELO PORTUGUES Y LAS INSTRUCCIONES DE BUCARELLI PARA LAS MISIONES DE GUARANIES
}

\author{
Ernesto J.A. Maeder*
}

La expulsión de los jesuitas de España y las Indias trajo modificaciones importantes en la administración de las Misiones. Ello se hizo perceptible, no solo en la creación del gobiemo interino de los pueblos guaraníes, sino también en los cambios sucesivos que experimentó su administración hasta ser confirmada por R.C. del 17.V.1803, así como las reformas estructurales que se aplicaron en el orden socio económico.

Las ordenanzas dictadas para ello constituyen un cuerpo legal del mayor interés para estudiar ese proceso. Sin embargo, no han sido muchos los estudios dedicados a ello, salvo el controvertido análisis que a su hora realizaron Pablo Hernández SJ y Julio Cesar González sobre las Instrucciones de Bucarelli de $1768 .^{1}$

El interés por rastrear las ideas que sirvieron de base a dicha legislación, nos llevó al estudio del caso brasileño, cronológicamente anterior, y que significó la aplicación del Directorio dictado por el gobemador Mendonça Furtado el 3.V.1757 a las Misiones jesuíticas de Grão Pará y Maranhão.

De la lectura del mismo surgieron no pocas coincidencias con la Instrucción dada por Bucarelli a las Misiones de Guaraníes el 23.VIII.1768. Un análisis comparado de ambos textos demostró, sin lugar a dudas, que el directorio portugués había servido de modelo a las normas elaboradas por Bucarelli una década después.

A partir de esa comprobación, que hasta la fecha no parece haber sido advertida por historiadores brasileños ni rioplatenses salvo Hemández, se estudiaron los antecedentes de ambas reformas, 
y luego las analogías y las diferencias de dichas normas. Las conclusiones a que llega el presente estudio indican que, las monarquías ibéricas, a pesar de las agudas diferencias que las separaban en materia de límites coloniales entre 1763 y 1768, procedieron respecto de las misiones jesuíticas con una similitud de propósitos mucho mayor que la inicialmente imaginada. El presente testimonio de las Instrucciones de Bucarelli, constituye una prueba elocuente de ello.

\section{Las Misiones de Pará y Marañon, y las reformas de Mendonça Furtado (1757-1758)}

La fundación y organización de las Misiones de Pará y Maranón, en la cuenca del Amazonas, constituye una de las más grandes empresas evangelizadoras cumplidas en el Brasil colonial. Sus características fueron distintas de las misiones del litoral (segunda mitad del siglo XVI y principios del XVII), o de las implantadas en la cuenca del río San Francisco (segunda mitad del XVII) o en Minas Gerais (siglo XVIII). En cambio se asemejan en mucho a las misiones de Guaraníes existentes en el dominio español.

El litoral atlántico de dicha región fue gradualmente ocupado por los portugueses, que edificaron Fortaleza (1612), San Luis de Belém (1616), Guarupá y Macapá (1631) y San José de Rio Negro (hoy Manaos, 1669) y desde allí disputaron palmo a palmo el territorio a los holandeses y franceses. La exploración del gran río, y las misiones que hacia el interior llevaron los carmelitas y franciscanos, y más tarde los jesuitas, permitieron abrir un amplisimo campo de trabajo apostólico entre las naciones indígenas de lengua tupí que poblaban la cuenca amazónica. ${ }^{2}$

De todas ellas, las misiones de los jesuitas fueron las que alcanzaron mayor desarrollo e importancia, tanto por el sistema original que introdujeron, como por su decidida oposición a la esclavitud de los indios por los colonos portugueses y mestizos. El P. Luis Figueira (1575-1643) fue el gran iniciador de esta obra, que contó con el apoyo de importantes religiosos, tales como los padres Antonio Vieira (1608-1697) y Juan Bettendorff (1628-1698), entre otros.

En 1636 se inició la misión en el Amazonas, y ya en 1661 había cobrado notable magnitud, al punto que los conflictos con 
los colonos y la relativa autosuficiencia de las aldeas dieron lugar a entredichos en 1661 y 1684.

El esfuerzo de los jesuítas había logrado una legislación favorable a los indios. En 1680 quedó prohibido el cautiverio de los mismos; se introdujo el reparto de tareas en tercios, y la administración de los pueblos por los padres de la Compañía sin ingerencia civil o militar. Y en 1686 se dictó el Regimento das Missóes do Estado de Maranhāo e Grão Pará, que regulaba la organización temporal y política de las aldeas, la designación de procuradores indígenas en Belém y San Luis, y la exclusión de blancos y negros en la vida comunal. ${ }^{3}$

En 1693 se deslindaron las jurisdicciones que correspondían a las diferentes órdenes religiosas que evangelizaban en esa región, correspondiéndole a los mercedarios y capuchinos la margen izquierda del Amazonas (el norte); a los jesuitas la margen derecha (el sur) y a los carmelitas la confluencia de los ríos Solimões, Negro y Madeira (oeste) hoy estado de Amazonia.

La vice provincia jesuítica de Marañón (1727) incrementó gradualmente su personal ( 76 misioneros en $1722 ; 128$ en 1740 y 155 en 1759) y con ellos llevó a cabo una importante obra misional. Decenas de aldeas, redacción de catecismos y vocabularios en lenguas indígenas y una actitud muy decidida frente a los colonos y funcionarios de la Capitanía en defensa del indio, caracterizaron su labor. La economía disponía de excedentes en especias y frutos agrícolas, que eran remitidos en canoas para su venta a través de las residencias de la orden. Los réditos de este tráfico, aunque revertía sus ganancias en la obra misional y el sostenimiento de los pueblos, no dejó de suscitar recelos en los colonos y competencia por parte del Estado.

Será precisamente como consecuencia de ello que las tensiones coloniales se acentuaron en el Marañón. La cuestión de la mano de obra de los indios y el virtual monopolio que las Misiones tenían de la producción amazónica, darán lugar a que se apliquen en esa región con inusitado rigor las reformas de Pombal, medidas que conluirán poco después con la expulsión de los jesuítas y el reordenamiento administrativo de las misiones. 
En 1751 se creó el Estado del Gran Pará y Marañón, con capital en Belém; al mando del mismo quedó Francisco Xavier Mendonça Furtado, hermano de Pombal. ${ }^{4}$ Este, elevado al rango de secretario de Estado del rey José I (1750), de primer ministro (1756), conde de Oeiras (1759), y más tarde, marqués de Pombal (1769), ejerció el poder de modo prácticamente absoluto. Dotado de una gran capacidad de trabajo, se propuso la reforma del Estado y el acrecentamiento del poder real, sin detenerse en la elección de los medios para ello. Su formación ideológica, impregnada de regalismo y de notoria antipatía hacia los jesuitas, lo llevó en breve plazo a chocar con el regimen de las misiones.

En un principio, y por sugestión de Mendonça Furtado, creó en 1755 la Compañía General de Comercio, con el objeto de introducir con exclusividad esclavos en la Capitanía y adquirir el monopolio de la producción colonial. La medida y su aplicación provocaron protestas incluso de los jesuitas, que desataron la irritación de Pombal. Como consecuencia de ello dispuso en 1757 el destierro de 21 padres de la Compañía. En ese mismo año. Mendonça Furtado dictó su Directorio, que fue aprobado por el Rey en 1758. Para ese entonces, las medidas persecutorias contra los jesuitas ya estaban en marcha, y el 19.I.1759 se dispuso el secuestro de sus bienes y la prisión de los padres, medidas que concluyeron el 3.IX.1759 con la extinción de la Compañía de Jesús en Portugal y en Brasil.

El Directorio das povoações dos índios do Pará e Maranhão, fue así el nuevo ordenamiento legal dado a las misiones. En parte, significó aplicar lo dispuesto en ley del 6.VI.1755 sobre libertad de los indios, favorecer sus matrimonios mixtos (mestizaje) y suprimir la administración temporal de los pueblos por los jesuitas. ${ }^{5}$ Dicho directorio rigió hasta 1798, en que fue derogado.

\section{Las reformas de Bucarelli para las Misiones de Guaranies (1768-1770)}

El caso de las Misiones de Guaraníes que los jesuitas habían fundado y mantenido bajo su atención pastoral entre 1609 y 1768 , es mucho más conocido y no requiere, al menos para el ámbito rioplatense, mas que una breve referencia a su historia y estructura.

Los 30 pueblos del Paraná y del Uruguay tenían una organización fundada en las Leyes de Indias y una administración religiosa y temporal que descansaba en gran medida en la labor de los padres, 
y las directivas de su Superior. Su economía, casi autosuficiente, contaba con la producción agrícola, las estancias de ganado y la elaboración artesanal de la yerba, tejidos y otros bienes.

La índole de los guaraníes hizo que, por sobre los cabildos y corregidores indígenas, hubiera una constantes tutela de los curas. Los indios, al igual que en Marañón, vivían con exclusividad en los pueblos, utilizaban su propia lengua y habían sido evangelizados conforme a pautas adaptadas a sus costumbres y afirmados por una catequesis asidua. Las labores eran distribuídas en forma regular, y en ellas participaban, según su edad, sexo y rango, todos los pobladores.

Esta relativa autosuficiencia económica y aislamiento de las poblaciones hispanocriollas, se compaginaba con la subordinación debida a los gobernadores de Asunción y Buenos Aires, que en muchas ocasiones requerían su ayuda para la construcción de obras públicas, o de contingentes militares contra los portugueses, los indios del Chaco o la Banda Oriental. A diferencia de los tupies de Maranhảo, los guaraníes no estaban obligados a trabajar para los colonos paraguayos o rioplatenses; contribuían con el tributo (1667) y los diezmos (1750), y la corona había reitarado en distintas ocasiones el aprecio que hacía de sus servicios y derechos (R.C. de 1743).

Sin embargo, los antiguos enfrentamientos con los encomenderos paraguayos por la mano de obra indígena, la competencia por la comercialización de la yerba y las sospechas maliciosas de que el esplendor de los pueblos misioneros se debía al atesoramiento de riquezas y a la explotación de los indios por los jesuitas, no habían desaparecido del todo. La aplicación del tratado de Madrid de 1750, que implicaba la cesión a Portugal de las 7 misiones orientales, así como el alzamiento guaraní que le sucedió (1754-1756) y las sospéchas de deslealtad que recayeron sobre los jesuitas, reavivaron las antiguas desconfianzas. A ello se agregó el espíritu fuertemente regalista de los ministros del rey Carlos III, así como el clima de animosidad contra la Compañía de Jesús que campeaba en la ilustración europea y dominaba en las cortes. La expulsión de los padres de Portugal (1759) y Francia (1764) facilitó una medida similar en España, que en 1767 dispuso su alejamiento de la península y de las Indias.

Como resultado de esa política, Bucarelli recibió en Buenos Aires las órdenes para proceder al estrañamiento de los jesuítas. ${ }^{6}$ 
Em virtud de esas disposiciones, el governador tomó sus medidas y procedió contra los jesuitas en el ámbito bonaerense, y más tarde en 1768, en las Misiones. Una nutrida correspondencia con el conde de Aranda permite seguir sus problemas financieros, las conversaciones preliminares con los corregidores guaraníes, el destino de los bienes secuestrados, la vigilancia sobre los partidarios de los jesuitas, la expedición a Misiones, las normas dictadas jara su gobierno, las listas de los expulsos, designaciones de gobernadores para el distrito, distribución de curas en los pueblos, propuestas de ascenso para sus subordinados y otros detalles de su cometido. ${ }^{7}$

Entre esas medidas se destaca la Instrucción, objeto principal de este estudio. Este ordenamiento era indispensable para llenar el vació político y administrativo que dejaban en Misiones los jesuitas

\begin{abstract}
"Establecido el metodo gubernativo que en lo provisional consideré mas conveniente para remediar los graves males que ocasionaban los jesuitas en lo espiritual de aquellos pobres habitantes, y para que en lo temporal lograsen mayor beneficio corrigiendo lo primero a cargo de los curas y lo segundo al de sus corregidores; cabildos y administradores, resolví mi retirada..."8
\end{abstract}

El carácter provisional que el propio Bucarelli asignó en principio a esta medida, está corroborado por las normas complementarias que, poco después se vió obligado a redactar. Tales, la Adición a mi instrucción, del 15.I.1770; la Instrucción que deben observar los administradores particulares, de igual fecha, y las Ordenanzas para regular el comercio de los españoles con los pueblos de indios Tapes y Guaranis, del 15.VI.1770.9

Pero, sin duda, la base de todas ellas es la Instrucción de 1768 , no solo por ser la primera, sino porque también define el espíritu de la reforma introducida y establece las medidas principales para alcanzarla. Bucarelli, acuciado por la prisa en ordenar las Misiones, con un conocimiento insuficiente de sus problemas y de la índole de los indios; prevenido frente a los jesuitas, no parece haber tenido tiempo de elaborar normas originales, sinó que al disponer del Directorio de Mendonça Furtado, se limitó a traducirlo y adaptarlo a las necesidades de su gobierno. 


\section{Comparación y parentesco entre ambas normas}

Tanto el Directorio como la Instrucción poseen analogías y evidente parentesco en la estructura general del cuerpo normativo, el orden dado a los temas, la similitud de las disposiciones y el vocabulario empleado. Un análisis prolijo permite verificarlo, y advertir en que medida Bucarelli incorporó, adaptó o desechó el modelo portugués que decidió seguir en su Instrucción.

a) La estructura y los temas de ambas normas

Si bien difieren en algunos aspectos formales, ambos ordenamientos guardan una gran analogía en su estructura. El Directorio posee 95 parágrafos e artículos, colocados en forma correlativa, sin preámbulo ni división en capítulos que distribuya sus contenidos. ${ }^{10} \mathrm{~A}$ su vez, Las Instrucciones, carecen de un ordenamiento en artículos numerados, o de capítulos que dividan su contenido. Esta diferencia, si bien dificulta la comparación, ya que el texto de Bucarelli solo admite 29 párrafos independientes, no impide observar que su estructura as idéntica y que los temas guardan el mismo orden (Ver anexo 1).

Sin embargo, conviene aclarar que ambas legislaciones se aplican en areas y pueblos diferentes, ya que el regimen legal existente en las Misiones de Marañón y Guaraníes difería bastante.

Mendonça Furtado, que ha dispuesto de mayor tiempo que Bucarelli para actuar, debió aplicar en 1757 el alvará del 7.VI.1755 que sustrajo a los jesuitas la administración temporal de sus misiones y otorgó libertad a los indios; en su reemplazo debió ofrecer una legislación que supliera el régimen abolido. Para ello, y dando por supuesta la incapacidad de los indios, creó un director en cada pueblo, nombrado por el gobernador del Estado, y dotado

"de bons costumes, zelo, prudencia, verdade, sciencia da lingua, e de todos os mais requisitos necesarios para poder dirigir con acerto os referidos indios, debaixo das ordens". ${ }^{11}$

El directorio de Mendonça Furtado, si bien deja subsistentes normas anteriores dictadas en tiempo de bonanza para los jesuitas, apunta 
a modificar de raíz el sistema de solidarismo misionero y abre los pueblos al comercio, fomenta su agricultura e introduce pautas culturales nuevas, tales como el uso del portugués, las escuelas públicas para ambos sexos, el pago de los diezmos, el auspicio del mestizaje y la tutela de los indios a través de los directores. ${ }^{12}$

Bucarelli, en cambio, si bien debió obrar con mayor premura, contaba a su favor con una legislación indiana abundante, a la que acudió en no pocas citas. Por otra parte, los pueblos poseían sus corregidores y cabildos; el trabajo indígena estaba exento de encomiendas; se pagaba desde tiempo atrás el tributo y los diezmos, y la jurisdicción de los gobernadores se dejaba sentir regularmente. Lo que Bucarelli buscará con su legislación, al reemplazar el régimen jesuítico y al igual que Mendonça Furtado, será escindir definitivamente el gobierno espiritual del temporal, asignando el primero a los sacerdotes y el segundo a los gobernadores y administradores.

\section{b) Los fines del nuevo ordenamiento}

Las finalidades señaladas en ambos casos, también guardan estrecha analogía.

Consisten, en primer lugar, en llevar a los indios al conocimiento de la fe, cuyo cometido quedaba reservado al obispo y a sus párrocos, y en segundo lugar, mejorar las condiciones de vida de los pueblos por medio de la vida civil, la agricultura y el comercio. Estos fines están expresados en los artículos 3-5 del texto portugués y en los párrafos 2-3 de Bucarelli. Un cotejo de ambos servirá para mostrar la dependencia del segundo texto respecto del primero.

\section{Directorio}

Instrucción

3. "Não se podendo negar, que os indios desde Estado se conservaräo até agora na mesma barbaridade, como se vivessem nos incultos sertões, em que nasceráo, praticando os pessimos, e abominaveis costumes do Paganismo, não só privados do verdadeiro conhecimento dos adoraveis mysterios da Nossa Sagrada Re-

"Dos son los objetos principales y que en las presentes circuns- 
ligiāo, mas até das mesmas conveniencias temporaes, que só se podem conseguir pelos meios da civilidade, da cultura, e do comercio: e sendo evidente, que as patemaes providencias do Nosso Augusto Soberano, se dirigem unicamente a Christianizar, e civilizar estes até agora infelizes, e miseraveis povos, para que, sahindo da ignorancia e rusticidade, a que se achão reduzidos, possão ser uteis a si, a dos moradores, e ao Estado; Estes dous virtuosos e importantes fins, que sempre foi a heroica empreza do icomparavel zelo dos Nossos Catholicos e Fidelissimos Monarcas, serão o principal objecto da reflexâo, o cuidado dos Directores."

4. "Para se conseguir, pois, o primeiro fim, qual he a christianizar os indios, deixando esta materia, por ser meramente espiritual, a exemplar vigilancia do Prelado desta Diocese. Recommendo unicamente a os Directores, que da sua parte dem todo o favor, e auxilio, para que as determinaçōes do dito Prelado, respectivas a direcção das $\mathrm{Al}$ mas, tenhäo a sua devida execuçâo; e que os indios tratem a os seus Parrocos com aquella veneração e respeito, que se deve a o seu alto caracter, sendo os mesmos Directores os primeiros, que com as exemplares acções da sua vida lhes persuadão a ob- tancias requieren una atenta reflexión: el primero es radicar a estos indios en un verdadero conocimiento de los adorables misterios de Nuestra Santa Fe. Es conforme a la ley $\mathrm{V} .^{\circ}$ del título y libro $I^{\circ}$ de los de Indias; pero este, como los medios conducentes a $\tan$ virtuoso e inmportante fin, se deben librar a la ejemplar vigilancia y prudencia del ilustrísimo obispo y de los eclesiásticos prelados de la diócesis a que correspondan estos pueblos; recomendando unicamente a Vd. que de su parte dé todo favor y auxilio para las determinaciones respectivas a la dirección de las almas tengan su debido cumplimiento, y para que los indios traten a sus parrocos con aquella veneración y respeto que exige su caracter y cuidado, estando si $\mathrm{Vd}$. en la inteligencia de que dichos parrocos no deben ya mezclarse en asunto diverso de su ministerio, por no haberles quedado otra ocupación que la concerniente al bien espiritual de las almas."

"El segundo objeto de la reflexión que encargo a Vd. debe ser proporcionar a estos indios aquellos beneficios y conveniencias temporales que se adquieren por los medios de la civilidad, de la cultura y del comercio..." 
servancia deste paragrafo."

5. "Em cuanto porém a Civilidade dos indios, a que se reduz a principal obrigação dos Directores por ser propria do seu ministerio; empregarão estes hum especialissimo cuidado em lhes persistir todos aquellos meios, que possão ser conducentes a tão util, e interessante fim, quaes são os que vou a referir."

Así como hubo analogía en los fines, existió también plena coincidencia en las recomendaciones para llevarlos a cabo. Tales, la introducción del idioma europeo.

6. “....Introduzir logo nos Povos conquistados o seu propio idio$\mathrm{ma}$, por ser indisputavel que este he hum dos meios mais efficazes para desterrar dos Povos rusticos a barbaridade."
3. “...es la base fundamental el introducir en estos pueblos el uso de nuestro propio idioma. Este es uno de los medios mas eficaces para desterrar la rusticidade."

la creación de escuelas para niños; el evitar que en ellas se use la lengua aborigen, y el guardar a los indios el respeto debido a sus rangos,

9. “...E tendo consideração a que nas povoações civis deve precisamente haver diversa graduaçāo de pessoas a proporção dos ministerios que exercitäo as quaes pede a razão, que sejāo tratadas com aquellas honras, que se devem aos seus empregos: Recommendo aos Directores, que assim em público, como em particular, horrem, e estimem a todos aquelles Indios, que forem Juizes OTdinarios, Vereadores, Principaes, ou occuparem outro qualquer posto honorifico..."
"Y considerando que en las repúblicas civilizadas debe haber diversa graduación de personas, a proporción de los ministerios que exercen, y los que persuade la razón sean tratados con aquellas honras que se debe a sua empleos, recomiendo mucho a Vd. que, así en público como en particular trate con distinción a los caciques, corregidores y a todos los indios que fueren jueces y ocuparen algún empleo honorifico." 
la promiscuidad en las viviendas, la suavidad en los medios para alcanzar el éxito de la reforma,

14. "Porem, como a reforma dos costumes, ainda entre homens civilizados, he a empreza mais ardua de conseguirse, especialmente pelos meios da violencia, e do rigor; e a mesma naturaleza nos ensina, que só se pode chegar gradualmente ao ponto da perfeiçảo, vencendo pouco a pouco os obstaculos, que a removem, e a difficultão: Advirto aos Directores, que para desterrar nos Indios as ebriedades, e os mais abusos ponderados, usem dos meios da suavidade, e da brandura;..."
"Pero, como la reforma de las costumbres y usos, aunque entre gentes civilizadas, es una de las empresas mas arduas de conseguir, principalmente por los medios de la violencia, y de la misma naturaleza nos enseña que solo se puede llegar gradualmente al punto de la perfección venciendo poco a poco los obstáculos que la remueven, o dificultades; es por lo tanto necesario que Vd. use de la mayor suavidad..."

El texto prosigue aludiendo a los vestidos lujosos (15-17), las normas relativas a la agricultura, los diezmos, el comercio y mano de obra (16-73) y las referentes a la administración de los pueblos (174-95), las que poseen también una gran semejanza con la Instrucción, que resultaría largo y tedioso reñalar, ya que el modelo portugués se mantuvo a la vista del legislador español de las Misiones.

\section{c) Concisión y adaptaciones de Bucarelli}

Sin embargo, y a pesar del puntual seguimiento del Directorio y de los extensos préstamos tomados, Bucarelli buscó adaptar y resumir en su Instrucción una buena parte del articulado portugués. Ello es perceptible tanto en las menores dimensiones que posee el escrito rioplatense (una tercera parte del lusitano), como en la mayor concisión que prevaleció en su prosa. ${ }^{13}$ En efecto, la minuciosidad y el detallismo de Mendonça Furtado, tan semejanto en ello a su hermano José Sebastián y que toma abrumadora la lectura del Directorio, desaparece en el texto de Bucarelli.

Un ejemplo de ello, puede verse en lo relativo a los diezmos, regulación de precios, comercio de los indios, establecimiento de los blancos en los pueblos y casamientos mixtos. ${ }^{14}$ 
A su vez, las adaptaciones son también frecuentes. Por una parte, las que aluden a las respectivas fuentes legislativas que informaron a uno y otro texto, y en el caso español, reiteradamente remitidas a las leyes de Indias. ${ }^{15}$ Obviamente, diferían también en alusiones a directores o gobernadores, según los casos.

Pero las adaptaciones más evidentes son aquellas que se refieren a aspectos concretos de la realidad de cada distrito: así, la propuesta de escuelas para niños y niñas en Maranhão y de sua correspondientes maestros y maestras, es resuelta por Bucarelli solo para varones y encomendando esa labor a los curas y compañeros. En cuanto al vestido de los indios, las exigencias del español son mayores, ya que no solo se escandaliza más que el portugués con el tipoi de las mujeres, sino que recomienda que vayan calzados y que se destierren las vestimentas costosas que tenían los danzantes y cabildantes, "por ridículas e inútiles". Al referirse a los cultivos, ciertas precisiones de lenguaje de Bucarelli indican su cuidado por adecuar el modelo a la realidad agraria misionera. ${ }^{16}$

Finalmente, también hay adaptaciónes de giros y expresiones que indican su búsqueda del vocabulario apropriado en la traducción: decir que los indios "viven como brutos" en sus estrechas casas, o que "no se puede negar que los indios de este Estado se conservan hasta achora en la misma barbaridad que se vivieran en los incultos sertones", son expresiones fuertes de Mendonça Furtado, evitadas por Bucarelli. Los ejemplos de este tipo pueden multiplicarse sin esfuerzo. ${ }^{17}$

\section{d) Las diferencias}

También existen notorias diferencias entre ambos ordenamientos. Por una parte, aquellos artículos y temas que no poseen aplicacjón en la otra jurisdicción. Por ejemplo, Bucarelli incluyó tres largos párrafos sobre ganadería, que no tienen correspondencia con el Directorio. Otro tanto ocurre con lo relativo a las remesas de frutos a la Administración General de Misiones en Buenos Aires, la preparación de padrones, búsqueda de minas o la referencia a las autoridades comunales.

A su vez, buena parte de los minuciosos artículos del Directorio, como los referidos a la prohibición de llamar negros a los indios (10), la aplicación de sobrenombres (11), los destierros por ebriedad (13), uso de la tierra (19-25), cobro de diezmos (28-31 
y 57), remisión de frutos (32-35), pesos y medidas (38), transporte en canoas (51-58), regulación del trabajo indígena fuera del pueblo y su retribución (59-73), edificios públicos (74), deserciones y fugas (75-79), radicación de blancos $(81-84 ; 86-87)$, casamientos mixtos (89-91) y responsabilidad de los directores, no tienen correspondencia en las normas de Bucarelli.

\section{Conclusiones}

De todo lo expuesto, se desprenden las siguientes conclusiones:

a) Las misiones que los jesuitas portugueses establecieron en la cuenca del Amazonas, al igual que las existentes en tierras españolas de Misiones, fueron secularizadas, modificándose en 1757 y en 1768 respectivamente, el régimen de gobierno y la administración de dichos pueblos indígenas.

b) Por tratarse de reinos independientes, no se había pensado en la utilidad de èncarar la comparación de las normas dictadas en uno y otro caso. Pero del estudio ahora emprendido, surge una evidente analogía entre ambas, resultando que el texto redactado por Mendonça Furtado sirvió de modelo a la Instrucción que Bucarelli dictó para Misiones una década después. La estructura y los temas del Directorio y la Instrucción, al igual que los fines del nuevo ordenamiento son semejantes y ponen de manifiesto la subordinación del texto español respecto del portugués.

c) Pense a ello, hay que destacar la mayor concisión lograda por Bucarelli, así como sus adaptaciones, que indican el esfuerzo realizado por acomodar la legislación a una realidad distinta de la que prevalecía en el Marañón.

d) Por último, este caso indica que las monarquías ibéricas, a pesar de las diferencias que mantenían en cuestiones de límites coloniales entre 1763 y 1768 , procedieron respecto de las misiones jesuíticas con una similitud de propósitos mucho mayor que la inicialmente supuesta. La legislación dada por Bucarelli a las misiones de Guaraníes en base al Directorio de Mendonça Furtado, es una prueba inequívoca de ello. 


\section{NOTAS}

${ }^{1}$ Pablo Hernández SJ. El extrañamiento de los jesuitas del Río de la Plata $y$ de las Misiones del Paraguay por decreto de Carlos III, en Colección de libros y documentos referentes a la Historia de América. t.VII, Madrid, 1908 y sobre todo, del mismo autor, Organización social de las doctrinas guaranies de la Compañía de Jesús, Barcelona 1913, vol. II, capítulos VI-VII. En página 240; Hernández sugiere que "las instrucciones fueron copia mas o menos retocada del Directorio..." dado que "se encuentran las mismas falsas imputaciones de esclavitud de los indios, de impiedad, de indecencia en casas y vestidos, el mismo establecimiento de administradores..." Las referencias parecen indirectas y tomadas del trabajo que cita, de Joachim Norberto de Souca Silva, Memoria histórica e documentada das aldeias de indios da Provincia de Rio de Janeiro, en Revista do Instituto Brazileiro (Rio de Janeiro, 1854), vol. XVIII, 153, y no el resultado de un cotejo formal. También, Julio César González, Notas para una historia de los treinta pueblos de Misiones. I, El proceso de expulsión de los jesuitas (1768), y II, El régimen gubernativo establecido después del extrañamiento jesuítico, ambos en Anuario de la Sociedad de Historia Argentina, vol. IV (Buenos Aires, 1942), pp.273-347 y vol. V (Buenos Aires, 1943-1945) pp.141-185.

${ }^{2}$ Estos indios posé́an una economía de subsistencia, basada en la agricultura por rozado del monte y complementada con la recolección de frutos silvestres, la caza y la pesca. Vivián en pequeñas aldeas de 364 viviendas colectivas (o malocas) y su organización social se estructuraba sobre rígidas normas de parentesco.

${ }^{3} \mathrm{El}$ Regimento del 1.IV.1680 y sus leyes anexas establecían una distribución de la labor de los indios en tres partes: una para los servicios de la propia aldea; otra para servir a los colonos blancos y mestizos y la tercera, para acompañar a los misioneros en su labor. Este ordenamiento y el del 1.XII.1686, en Serafimr Leite, História da Companhia de Jesus no Brasil, Rio de Janeiro, 1937-1949, t.VI, pp.63-67 y 369-375. Un resumen del mismo en José O. Beozzo, Leis e regimentos das Missōes. Política indigenista no Brasil. São Paulo, Ed. Loyola, 1983, pp.106-120.

${ }^{4}$ El nepotismo de Pombal era desembozado, ya que en 1755 colocó a su sobrino Joaquim Melo e Povoas al frente de la Capitanía de San José de Rio Negro.

${ }^{5}$ Leyes del 4.IV.1755 y del 6-7.VI.1755. Poco despues, la libertad de los indios se ampliará el 8.V.1758 a todo el Brasil. La libertad de los dichos indios suponf́a abolir la protección que para ellos habían logrado los jesuitas y dejarlos a merced de las autoridades y colonos. Bibliografía general sobre el tema, además de las obras citadas de Serafim Leite y José O. Beozzo, Pedro Calmon, História do Brasil, Rio de Janeiro, 1959, vols. III-IV; Sergio Buarque de Holanda, História geral da civilização brasileira (dir.). Época colonial, Sảo Paulo, 1960, vols. I-II y últimamente, Ed. Hoornaert et alli, História da Igreja no Brasil. Ensaio de interpretaçâa a partir do povo. 3.' ed. Petrópolis, 1983, i॰ Época.

${ }^{6}$ Eran la R.C. del-27.II.1767, las órdenes del 5.IV y las instrucciones del conde de Aranda, la adición a las mismas y la carta circular correspondiente, todas fechadas el 1.III.1767; en Francisco Javier Brabo. Collección de documentos relativos ala expulsión de los jesuitas de la República Argentina y del Paraguay etc. Madrid, 1872, pp.3-17. 
${ }^{7}$ Francisco Javier Brabo, Colección cit. pp.26-290.

${ }^{8}$ Francisco Javier Bravo, Colección cit. p.194. La “Instrucción a que se deberán arreglar los gobernadores interinos que dejo nombrados en los pueblos de indios guaranís del Uruguay y Paraná, no habiendo disposición contraria de S.A.", está fechada en Candelaria el 23.VIII.1768, en Colección cit. pp.200-210.

${ }^{9}$ Carta de Bucarelli al conde de Aranda del 14.X.1768, en Colección cit, p.198. Las disposiciones citadas en ibidem, pp.303-324; 297 y 324-345.

10Fechado en Pará el 3.V.1757 y firmado por el gobernador y Capitán general Francisco Xavier Mendonça Furtado, fue confirmado por alvará del 17.VIII.1758. El ejemplar utilizado en el texto impreso en Lisboa en 1758, en 38 páginas. Fue reproducido por Antonio Delgado da Silva en su Coleção da legislação portuguesa, Lisboa, 1830, t.I, pp.507-530 y el alvará citado en pp.634-635. Agradecemos al P. Arthur Rabuske SJ la copia de este texto y al Dr. Arno Alvarez Kern la fotocopia del ejemplar de 1758 .

11 Directorio cit. art. 1.

${ }^{12} \mathrm{El}$ artículo 9 alude a una ley del $1.1 \mathrm{II} .1701$ y los artículos 16 y 94 a los parágrafos IX y XIII del Regimento de 1686.

${ }^{13} \mathrm{El}$ Directorio posee aproximadamente 11.500 palabras, frente a las 4.400 de la Instrucción de Bucarelli.

${ }^{14}$ En el Directorio, articulos $27-31 ; 37-38 ; 40-43 ; 80-87$ y $88-91$, que se corresponden con los párrafos de la Instrucción.

${ }^{15}$ En la Instrucción, las citas de leyes corresponden al libro I, título 1, ley 5 ; al libro VI, título 1 , leyes $2,18,19,24$ y 25 ; y libro VI, titulo 3 , ley 1. Asimismo, la R.C. del 26.VIII.1748 sobre diezmos, y la R.C. del 11.IX.1766 sobre libertad de los indios.

${ }^{16}$ Algunos términos, como "chacarerías", sembrados comunes y particulares, la omisión de todo lo referido a las especias y drogas extrañidas del sertāo, etc.

*Instituto de Investigaciones Geohistoricas

Casilla de Correo, 438

3500 Resistencia - Argentina 